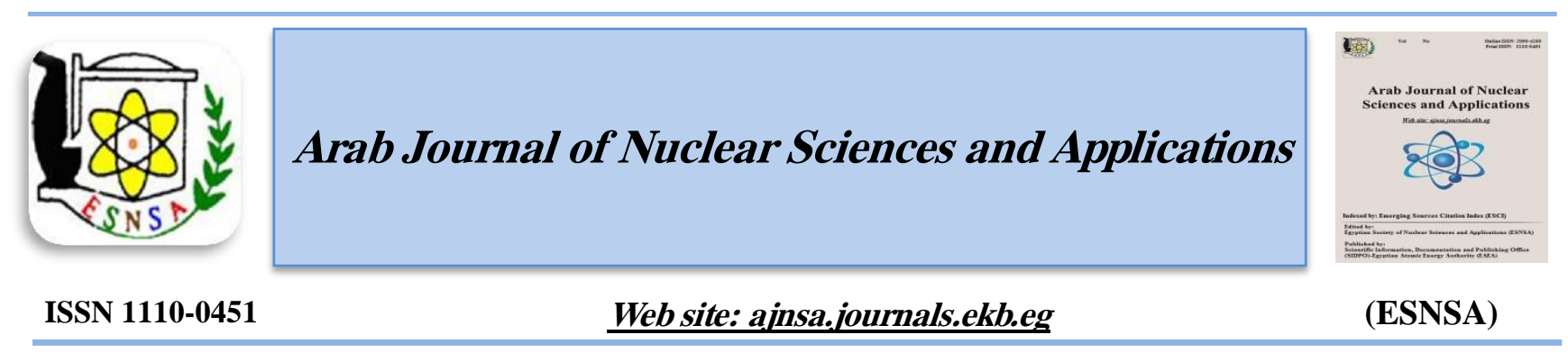

\title{
The Influence of the Gas Mixing Ratio on Some Characteristics and Reaction Rate Coefficients of $\mathrm{Ar} / \mathrm{N}_{2}$ and $\mathrm{He} / \mathrm{N}_{2}$ DC Plasma35
}

\author{
Naglaa M El-Sayed, and Omar F. Farag \\ Physics Department, Faculty of Science, Zagazig University
}

\begin{abstract}
Received $1^{\text {st }}$ Sep. 2018 The aim of this study is to analyze the relation between the reaction rate coefficients, hence the Accepted $24^{\text {th }}$ Mar. 2019 production of active species, and the gas mixing ratio in a comparative way between $A r / N_{2}$ and $H e / N_{2}$ gaseous mixtures. The $\mathrm{Ar}$ and He contributions ranged from 0 to $100 \%$ at a total gas pressure of 0.4 Torr and a reduced electric field $\mathrm{E} / \mathrm{N}$ of $610 \mathrm{Td}$. Langmuir probe is employed to measure electron temperature. The results showed that adding Ar to $\mathrm{N}_{2}$ plasma reduced both the discharge operating voltage and the electron temperature. However, an opposite action is obtained on Adding He. Also, Ar can induce the dissociation of molecular nitrogen and increase the production of nitrogen atoms, however it has an insignificant effect on the nitrogen ionization mechanism. On the other hand, He addition enhances the production of $\mathrm{N}_{2}^{+}, \mathrm{N}^{+}$and $\mathrm{N}$-atoms through ionization, ionization dissociation and dissociative reaction, however it has a decreasing effect on the dissociative recombination mechanism
\end{abstract}

Keywords: DC plasma/ Ionization/ Dissociation/ Rate coefficients

\section{Introduction}

Nitrogen plasma is known for its important technological applications in various fields of our life including metallic nitriding, surface modifications of different materials such as polymers and their composites, and sterilization of medical tools. Therefore, until now, a huge number of both theoretical and experimental studies came out investigating and characterizing nitrogen plasmas demonstrating its effects on different materials [1-4]. Some applications of $\mathrm{N}_{2}$ plasma, such as surface etching and thin film nitriding, heating and biological sterilization count on the existence of nitrogen in its atomic form. Dissociation of $\mathrm{N}_{2}$ into $2 \mathrm{~N}$ is not that easy in case of pure nitrogen due to the strong N-N bond ( 945 $\mathrm{KJ} / \mathrm{mole}$ ) [5]. However, the process can be enhanced by adding noble gases such as $\mathrm{He}$, Ar or $\mathrm{Ne}$. Addition of such gases can affect the discharge characteristics (the electron temperature, electron / ion number density and electron energy distribution function), consequently, changes the excitation, ionization and dissociation rate coefficients, and hence, enhancing the concentration of active species.

Adding Ar or He into N2 plasma has been used to regulate the electron temperature and enhance the number of active species in an inductively coupled plasma [6]. K. Abbas et.al [7] added Ar to N2 in DC glow discharge and concluded that $60 \% \mathrm{Ar}$ concentration in $\mathrm{Ar} / \mathrm{N} 2$ plasma is most suitable for the nitriding of silicon due to the production of a large number of active species which facilitate the nitrogen diffusion. Helium is considered one of the powerful Penning reagents for plasma species to be exited, ionized and dissociated through inelastic collisions. Also, due to its low mass, He-atoms are characterized by their lower efficiency of cathodic sputtering so that when added to another gas (N2 in the present paper) no increase in the impurity level would be expected [6, 8]. Naveed et. al [9] investigated the effect of changing $\mathrm{He}$ concentration in a capacitive RF He/N2 plasma on

Corresponding author: nagla68mohammed@gmail.com

DOI: 10.21608 /ajnsa.2019.4970.1115

(C) Scientific Information, Documentation and Publishing Office (SIDPO)-EAEA 
the $\mathrm{N} 2$ active species (N2(C $3 \Pi u)$ and $\mathrm{N}_{2}^{+}\left(\mathrm{B} 2 \Sigma_{\mathrm{u}}^{+}\right)$) and different plasma characteristics. They detected a considerable increase in the active species concentration upon increasing He percentage in the gas mixture.

In a previous study [10] the characteristics of $\mathrm{Ar} / \mathrm{N}_{2}$ and $\mathrm{He} / \mathrm{N}_{2}$ DC-plasma were measured using single cylindrical Langmuir probe. The study gave quantitative measurements of the electron temperature, $\mathrm{T}_{\mathrm{e}}$, electron number density, $\mathrm{n}_{\mathrm{e}}$, ion number density, $n_{i}$, plasma potential, $V_{p}$, electric field distribution, $\mathrm{E}$, and electron energy distribution function, EEDF as a function of $\mathrm{Ar}$ and $\mathrm{He}$ fractions in the discharge. As a complement of this study, the present work aims to investigate the effect of changing $\mathrm{He}$ and $\mathrm{Ar}$ contents, in a DC $\mathrm{N}_{2}$ plasma, on different reaction rate coefficients utilizing the previously obtained values of the plasma parameters.

\section{Materials and Method}

The schematic diagram describes the discharge unit is given in an earlier publication [11]. It consists of a Pyrex glass tube of $18 \mathrm{~cm}$ in length and $13 \mathrm{~cm}$ in inner diameter. The tube contains two parallel copper electrodes of $5 \mathrm{~cm}$ in diameter and $7 \mathrm{~cm}$ separation distance. A continuous flow of $\mathrm{He} / \mathrm{N}_{2}$ and $\mathrm{Ar} / \mathrm{N}_{2}$ is allowed to enter the tube throw a needle valve after evacuating the tube to a base pressure $10^{-3}$ Torr. The total gas pressure is recorded by Pirani gauge and kept constant at 0.4 Torr during the measurements. The calculated reduced electric field $\mathrm{E} / \mathrm{N}$ was fixed at about 610 Td.
The Lnagmuir probe, employed for plasma diagnostics, made of tungsten wire of $0.3 \mathrm{~mm}$ in diameter and $5 \mathrm{~mm}$ exposed length supported by a ceramic tube concentric in a Pyrex glass one. The probe is allowed to enter a discharge tube from an opening in its middle. The electron temperature, $\mathrm{T}_{\mathrm{e}}$, is determined at different $\mathrm{Ar}$ and $\mathrm{He}$ concentrations in the gas mixtures, from the slope of the $\ln (\mathrm{I})-\mathrm{V}$ curve of the probe in the transition region between the floating potential and plasma potential by the following equation [12]:

$$
T_{e}=e /\left(k_{B} d \ln (I) / d V\right)
$$

Where $\mathrm{e}, \mathrm{K}_{\mathrm{B}}, \mathrm{I}$ and $\mathrm{V}$ are the electronic charge, Boltzmann constant, probe current and probe voltage respectively.

The characterization of electrons, atoms, radicals, ions and molecules in $\mathrm{Ar} / \mathrm{N}_{2}$ and $\mathrm{He} / \mathrm{N}_{2}$ mixtures is needed to understand and control the behavior of these different plasma species for their relevance for technological applications. In cold plasma, the main primary reactions by electron impact on atoms and molecules are ionization, excitation to higher energy levels and dissociation. The rate coefficients, $\mathrm{K}_{\mathrm{s}}$, of these reactions can be obtained by integrating the product of electron velocity times the cross section of each process over an estimated Maxwellian distribution [13].

$$
k_{s}=\langle\sigma(v) v\rangle_{v}=4 \pi \int_{0}^{\infty} \sigma(v) v^{3} f(v) d v
$$

Different reactions and their relate rate coefficients are obtained from the literature and listed in Table (1).

\begin{tabular}{|c|c|c|c|}
\hline & $\begin{array}{c}\text { Reaction } \\
\text { mechanism }\end{array}$ & Rate coefficient $(\mathrm{cm} 3 / \mathrm{s})$ & Reference \\
\hline R1 & $\begin{array}{l}N_{2}+e \\
\rightarrow N^{+}+N+2 e\end{array}$ & $\begin{array}{r}-5.68 \times 10^{-12} \mathrm{~T}_{\mathrm{e}}+8.57 \times 10^{-12} \mathrm{~T}_{\mathrm{e}}^{2}-4.11 \times 10^{-12} \mathrm{~T}_{\mathrm{e}}^{3} \\
+7.26 \times 10^{-13} \mathrm{~T}_{\mathrm{e}}^{4}-3.09 \times 10^{-14} \mathrm{~T}_{\mathrm{e}}^{5}\end{array}$ & 14 \\
\hline $\mathbf{R 2}$ & $N_{2}+e \rightarrow N_{2}^{+}+2 e$ & $\begin{array}{r}1.01 \times 10^{-10} \mathrm{~T}_{\mathrm{e}}-1.13 \times 10^{-10} \mathrm{~T}_{\mathrm{e}}^{2}+3.14 \times 10^{-11} \mathrm{~T}_{\mathrm{e}}^{3} \\
-7.52 \times 10^{-13} \mathrm{~T}_{\mathrm{e}}^{4}-5.14 \times 10^{-14} \mathrm{~T}_{\mathrm{e}}^{5}\end{array}$ & 14 \\
\hline $\mathbf{R 3}$ & $N_{2}+e \rightarrow 2 N+e$ & $1.18 \times 10^{-8} \times T_{e}^{0.5} \times e^{-13.3 / T e}$ & 15 \\
\hline $\mathbf{R 4}$ & $N_{2}^{+}+e \rightarrow N+N$ & $2.8 \times 10^{-7} \times\left(0.026 / T_{e}\right)^{0.5}$ & 16 \\
\hline
\end{tabular}

Table (1): Reactions and rate constants of N2 plasma

Where R1, R2, R3 and R4 designated to the following reactions respectively: the ionization dissociation reaction with rate coefficient $K_{i}^{\text {diss }}$, the ionization reaction with rate coefficient $K_{i}$, the dissociative reaction with rate coefficient $K_{d}$, the dissociative recombination with rate coefficient $\mathrm{K}_{\mathrm{d}}{ }^{\mathrm{r}}$ 


\section{Results and Discussion}

The variations of discharge operating voltage as a function of $\mathrm{Ar}$ and $\mathrm{He}$ percentages at fixed current and pressure are depicted in Fig. (1). This figure shows a slightly decreasing voltage with increasing Ar percentage; however, an increasing behavior is obtained in case of He. These behaviors can be explained in the light of the fact that although $\mathrm{Ar}$ and $\mathrm{N}_{2}$ have nearly the same ionization potentials ionization cross sections $(\approx 15.7 \mathrm{eV}$ and $\approx$ $2.5 \times 10^{-20}$ ) [17], the decreasing behavior of the operating voltage with Ar contribution refers to the fact that in case of pure noble gas plasmas, the main ionization mechanism is the step wise one,

$$
\mathrm{e}+\mathrm{Ar} \rightarrow \mathrm{e}+\mathrm{Ar}^{*}, \mathrm{e}+\mathrm{Ar}^{*} \rightarrow 2 \mathrm{e}+\mathrm{Ar}^{+} .
$$

Where Ar* designated for the Ar metastable exited state. However, the situation for $\mathrm{N}_{2}$, as a molecular gas, is different because there are some additional complexities for molecular processes due to the increased internal degrees of freedom i.e. electron energy loss channels, such as vibrationally and rotationally excited states in addition to the molecular dissociation mechanisms. This effect results in reduction in the operating discharge voltage needed to sustain the discharge. In contrary to Ar addition, He addition results in increasing the discharge voltage. The reason for this behavior is attributed to the fact that for $\mathrm{T}_{\mathrm{e}}$ within the range 1$20 \mathrm{eV}$, helium has electron collision cross section of about $2 \times 10^{-21} \mathrm{~m}^{2}$ in its ground state which is smaller than that of $\mathrm{N}_{2}$ of $1.2 \times 10^{-19} \mathrm{~m}^{2}$ [18]. So that in order to sustain the discharge, the voltage has to be increased.

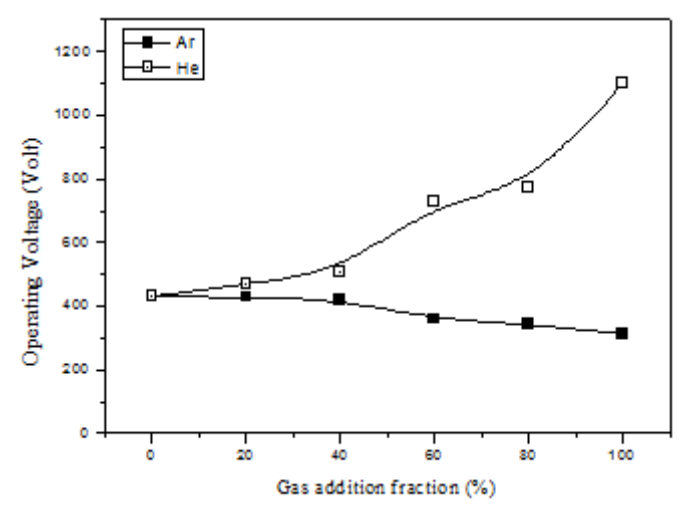

Figure (1): variation of discharge operating voltage as function of Ar and He percentage
Figure (2) demonstrates the variation of $\mathrm{T}_{\mathrm{e}}$ with the addition percentage of both $\mathrm{Ar}$ and $\mathrm{He}$ in $\mathrm{N}_{2}$ discharge. In spite of the similarity of ionization potentials and ionization cross sections of both $\mathrm{Ar}$ and $\mathrm{N}_{2}, \mathrm{~T}_{\mathrm{e}}$ showed a slight decrease ranging from 4.5 to $1.5 \mathrm{eV}$, with an increase of Ar ranging from 0 to $100 \%$. This result was interpreted as according to a previous work by the authors [10] as the measurements of the electron number density, $n_{e}$ and EEDF showed that, argon addition resulted in increasing the values of $n_{e}$, and hence the electronelectron collision frequency is expected to be increased. This behavior, in turn, tends to deplete electrons in the "hot tail" and the EEDF relaxes to Maxwellian distribution, as a consequence, $\mathrm{T}_{\mathrm{e}}$ decreases [19]. This result agrees with the measurements of F.U. Khan et.al [20,21], they showed that $\mathrm{T}_{\mathrm{e} \text {-tail }}$ obtained from EEPF and the electron temperature obtained from spectroscopic line-ratio technique decreases with the mixing ratio in $\mathrm{Ar} / \mathrm{N}_{2}$ inductivly coupled discharge and they attributed their result to the increase of total ionization cross sections (inelastic collisions). In $\mathrm{H}_{2} / \mathrm{Ar}$ plasma, M. Sode et.al [22] obtained the same result with increasing the Ar contribution and attributed this behavior to the increase in the effective ionic mass from 2.7 amu (for $\mathrm{H}_{2}$ ) to 40 amu (for Ar). In the proposed mixture, the effective mass increased from 28.02 amu (for $\mathrm{N}_{2}$ ) to $40 \mathrm{amu}$ (for Ar). Due to the same reason for increasing the operating voltage, increasing $\mathrm{He}$ content will reduce electron collision frequency, and this gives the electrons the chance to move in the electric field with a larger mean free path, consequently, increasing their kinetic energy and hence their temperatures. According to the current results, $\mathrm{T}_{\mathrm{e}}$ increased from 4.5 to $8.9 \mathrm{eV}$ through the whole range of He addition as shown in Fig. (2). Qing Xiong et.al [23] concluded that increasing of the electron temperature, in case of He being more than Ar and any other noble gas attributed to the existence of the metastable $2^{1} \mathrm{~S}$ in singlet state. Then electrons could have the ability to accumulate a high energy in the external electric field consequently, induce the ionization and/or excitation of He atoms through collisions. M.A. Naveed et.al [18], by using Langmuir probe and OES, demonstrated that the electron temperature, electron density and concentration of active species increase with increasing the helium contribution in $\mathrm{RF} \mathrm{He} / \mathrm{N}_{2}$ plasma. 
Ionization rate coefficients, $K_{i}$ and $K_{i}^{\text {diss }}$, due to the reactions $\mathrm{R} 1$ and $\mathrm{R} 2$ as a function of Ar content are represented in Fig. (3-a). As can be seen from the figure, an increase in the Ar content results in a noticeable influence on the ionization rates due to $\mathrm{R} 1$ and R2. As the rate coefficients have a decreasing trend with increasing Ar content. However, a slight increase (nearly a saturation trend) in both rates at the concentration (Ar 40\% for $\mathrm{R} 1$ and $50 \%$ for R2) was observed. The ionization dissociation, due to $\mathrm{R} 2$, is about two orders of magnitude higher than the ionization rate due to $\mathrm{R} 1$. The deceasing behavior of $\mathrm{K}_{\mathrm{i}}$ and $\mathrm{K}_{\mathrm{i}}^{\text {diss }}$ with $\mathrm{Ar} \%$ agrees with previous works in the literature [24,25]. As they concluded that argon addition does not affect the nitrogen ionization mechanism and attributed this conclusion to the fact that the energy of the Ar matastable atoms of ${ }^{3} \mathrm{P}_{0}(11.72 \mathrm{eV})$ and ${ }^{3} \mathrm{P}_{2}(11.55 \mathrm{eV})$ are lower than the threshold ionization energy of $\mathrm{N}_{2}$ molecules (which is $15.57 \mathrm{eV}$ for $\mathrm{R} 1$ and $24.5 \mathrm{eV}$ for $\mathrm{R} 2$ ).
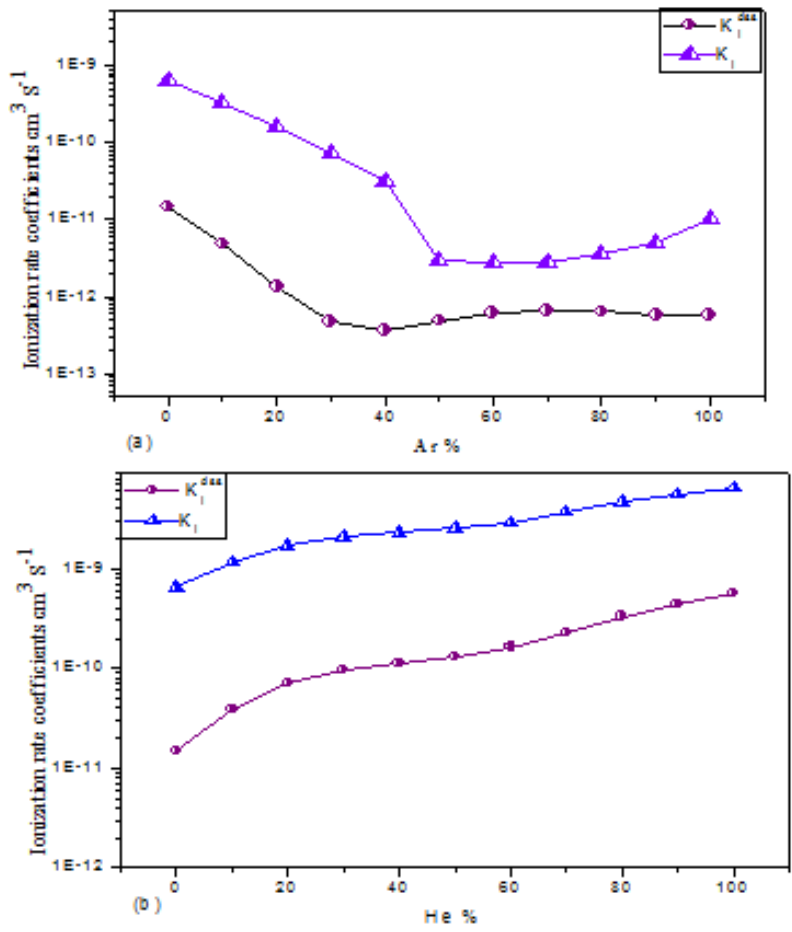

Figure (3): Ionization rate coefficients of $\mathrm{N}_{2}$ as a function of $\mathrm{Ar}(\mathrm{a})$ and $\mathrm{He}(\mathrm{b})$ content in the mixture

On the other hand, Fig. (3-b) demonstrates that on increasing $\mathrm{He}$ fraction in the gas mixture $\mathrm{k}_{\mathrm{i}}$ and $\mathrm{K}_{\mathrm{i}}^{\text {diss }}$ showed a similar increasing trend due to both $\mathrm{R} 1$ and R2 with values due to R2 are one order of magnitude higher than that due to R1. This behavior can be interpreted as: with increasing $\mathrm{He}$ fraction in the gas mixture, the scattering of electrons with $\mathrm{He}$ atoms increases, in addition to the reduction of collision frequency because of the smaller helium collision cross section. Hence, the electron energy increases and it can ionize nitrogen molecules upon collision with it. The production of $\mathrm{N}_{2}^{+}$in $\mathrm{He} / \mathrm{N}_{2}$ gas mixture is previously reported [26, 27] to be mainly due to Penning ionization of $\mathrm{N}_{2}\left(\mathrm{X}^{2} \sum_{\mathrm{g}}^{+}\right)$by metastable helium atoms. As the He atoms of metastable states $2^{3} \mathrm{~S}_{1}$ and $2^{1} \mathrm{~S}_{1}$ having the energies $19.8 \mathrm{eV}$ and $20.6 \mathrm{eV}$ respectively, both are higher than the threshold ionization energy of the $\mathrm{N}_{2}$ molecule $(15.57 \mathrm{eV})$.
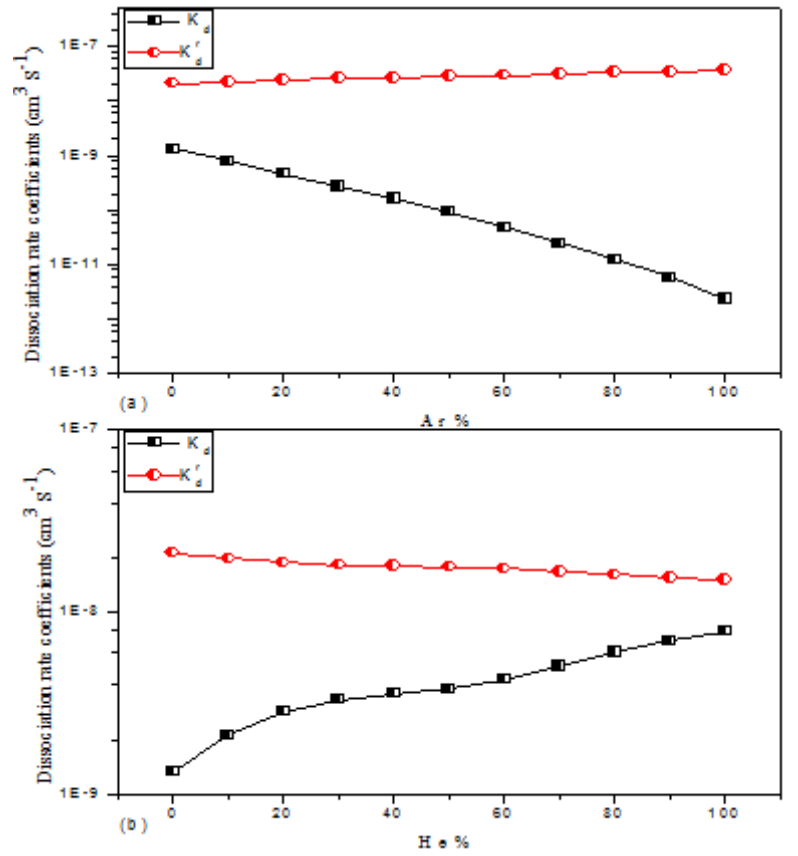

Figure (4): Dissociation rate coefficients of $\mathrm{N}_{2}$ as a function of $\mathrm{Ar}$ (a) and He (b) content in the mixture

Dissociative rate coefficients, $K_{d}$ and $K_{d}^{r}$, due to the reactions $(\mathrm{R} 3, \mathrm{R} 4)$ for $\mathrm{N}_{2}$ plasma as a function of $\mathrm{Ar}$ addition are presented in Fig. (4-a). The dissociation due to R3 showed a decreasing behavior, however due to R4, it slightly increased with increasing $\mathrm{Ar}$ fraction. Adding $\mathrm{Ar}$ to $\mathrm{N}_{2}$ plasma may create additional destruction channels for charged particles. Because of the similar values of their ionization potential, charge transfer reaction may be possible $\mathrm{Ar}^{+}+\mathrm{N}_{2} \rightarrow \mathrm{Ar}+\mathrm{N}_{2}^{+}$. This reaction may be followed by dissociative recombination $\mathrm{N}_{2}^{+}+\mathrm{e} \rightarrow \mathrm{N}+\mathrm{N}[28]$.

M.A. Song et. al. [29] investigated the effect of Ar fraction on the properties of low-pressure 
inductively coupled nitrogen-argon plasmas applying both Langmuir probe and OES techniques. In agreement with the present results, they observed that increasing the Ar \% leads to a slight increase of the emission intensity from $\mathrm{N}$ atoms, which is an indication of the increase of dissociation rate coefficient. They explained that this could be attributed to the fact that with an increase of Ar content, the Penning excitation and Penning dissociation, due to Ar metastables, increase the densities of the excited states of $\mathrm{N}$ atoms.

Dissociative rate coefficients due to the reactions (R3, R4) for $\mathrm{N}_{2}$ plasma as a function of $\mathrm{He}$ addition are presented in Fig. (4-b). It is clear from this figure that $\mathrm{K}_{\mathrm{d}}$ has an increasing trend, however $\mathrm{K}_{\mathrm{d}}^{\mathrm{r}}$, shows a slightly decreasing tendency. The obtained increasing behavior of $\mathrm{K}_{\mathrm{d}}$ is partially in agreement with Maria Younus et. al [30]. They detected the increase of $\mathrm{N}$-atoms intensity with increasing the $\mathrm{He}$ concentration above $56 \%$ in a $\mathrm{RF} \mathrm{He}-\mathrm{N}_{2} / \mathrm{Ar}$ plasma and attributed this behavior to their measurements of the EEPF which showed that the density of both high and low energy electrons increased simultaneously with increasing $\mathrm{He} \%$. The high energy electrons enhance the production of $\mathrm{N}$-atoms through the reaction $\mathrm{R} 3$ $\left(\mathrm{N}_{2}+\mathrm{e} \rightarrow 2 \mathrm{~N}+\mathrm{e}\right)$, however, the low energy electrons enhance the production of $\mathrm{N}$-atoms through the reaction $\mathrm{R} 4$ $\left(\mathrm{N}_{2}^{+}+\mathrm{e} \rightarrow \mathrm{N}+\mathrm{N}\right)$. According to a previous work by the authors [10], the measured EEDF showed a decided shift of the distribution towards the higher energy and slight increase in the density of high energy electrons, however, the low energy electrons showed a decreasing density. This can explain the obtained result of the decreased $\mathrm{K}_{\mathrm{d}}^{\mathrm{r}}$, and the increased $\mathrm{K}_{\mathrm{d}}$ with He concentration.

\section{Conclusion}

The variations of discharge operating voltage and electron temperature of $\mathrm{N}_{2}$ DC plasma was investigated as a function of plasma composition. It was found that the values of discharge voltage and electron temperature tend to decrease with increasing $\mathrm{Ar} \%$, however their values had an increasing behavior with increasing $\mathrm{He} \%$.

The effect of gas composition on the different reaction rate coefficients also had been investigated and according to the proposed experimental condition, argon can induce the dissociation of molecular nitrogen and increase the production of nitrogen atoms however, it has no touchable effect on the nitrogen ionization mechanism. On the other hand, helium addition enhances the production of $\mathrm{N}_{2}^{+}, \mathrm{N}^{+}$and $\mathrm{N}^{-}$atoms through ionization, ionization dissociation and dissociative reaction, however it has a decreasing effect on the dissociative recombination mechanism.

\section{References}

1-Farag, O.F. (2018) Comparison of the effect of plasma treatment and gamma ray irradiation on PS$\mathrm{Cu}$ nanocomposite films surface, Results in Physics, 9, 91-99.

2-Pieter, C., Mahtab. A., Wannes, N., Heidi, D. , Rino. M., and Nathalie, De G. (2018) Surface Treatment of PEOT/PBT (55/45) with a Dielectric Barrier Discharge in Air, Helium, Argon and Nitrogen at Medium Pressure, Materials, 11 (391), 1-15.

3-EL-Sayed N.M., Reda, F.M., Farag, O. F., Nasrallah, D. A. (2017) Surface analysis of nitrogen plasma-treated C60/PS nanocomposite films for antibacterial activity, J Biol Phys. 43 (2), 211224.

4-Karama , L., Casettaa , M., Chihiba , N.E., Bentiss, F., Maschkea , U., Jama, C. (2016) Optimization of cold nitrogen plasma surface modification process for setting up antimicrobial low density polyethylene films, Journal of the Taiwan Institute of Chemical Engineers, 64, 299-305.

5-Luo, Y.R. (2007) Comprehensive Handbook of Chemical Bond Energies, CRC Press, Boca Raton, FL.

6-Kang Zheng-De and Pu Yi-Kang (2002), Electron Temperature Control in Inductively Coupled Nitrogen Plasmas by Adding Argon/Helium, Chin. Phys. Lett., 19 (8), 1139.

7-Abbas, K., Ahmad, R., Khan, I.A., Saleem, S., Ikhlaq, U. (2016) Influence of Argon Gas Concentration in N2-Ar Plasma for the Nitridation of Si in Abnormal Glow Discharge, International Journal of Chemical, Molecular, Nuclear, Materials and Metallurgical Engineering, 10 (7), 858-870.

8-Wagatsuma, K. (2001)Emission characteristics of mixed gas plasmas in low-pressure glow discharges, Spectrochim Acta B, 56 (5), 465-486.

9-Naveed, M.A., Rehman, N.U., Zeb, S., Hussain, S. and Zakaullah, M. (2008) Langmuir probe and spectroscopic studies of RF generated heliumnitrogen mixture plasma, Eur. Phys. J. D 47, 395-402

10-Mansour, M.M., El-Sayed, N.M., Farag, O.F., and Elghazaly, M. H. (2013) Effect of $\mathrm{He}$ and $\mathrm{Ar}$ Addition on $\mathrm{N}_{2}$ Glow Discharge Characteristics and Plasma Diagnostics, Arab Journal of Nuclear Science and Applications, 46(1), 116-125. 
11-Naglaa, M.E., Magdy, M.M., Omar, F.F., and Mohammed, H.E. (2012) N2, N2-Ar and N2-He DC Plasmas for the improvement of Polymethylmethacrylate surface wettability, Adv. Appl. Sci. Res., 3(3).1327-1334.

12-Qayyum, A., Ikram, M., Zakaullah, M., Waheed, A., Murtaza, G., Ahmad, R., Majeed, A., Khattak, N.A.D., Mansoor, K., and Chaudhry, K.A. (2003) Characterization of argon plasma by useof optical emission spectroscopy and Langmuir probe measurements, Int. J. Mod. Phys. B, 17, 1-11

13-Gudmundsson J.T, Notes on the electron excitation rate coefficients for argon and oxygen discharge (2002) Department of electrical and computer engineering, university of Iceland, Iceland.

14-Straub, H.C., Renault, P., Lindsay, B.G., Smith, K.A., and Stebbings, R.F. (1996) Absolute partial cross sections for electron-impact ionization of $\mathrm{H} 2$, N2, and $\mathrm{O} 2$ from threshold to $1000 \mathrm{eV}$ Phys. Rev. A, 54 (3), 2146-2153.

15-Cosby, P.C. (1993) Electron-impact dissociation of nitrogen, J. Chem. Phys., 98 (12), 9544-9553.

16-Kossyi, I.A., Kostinsky, A. Yu, Matyevev, A.A. and Silakov, V.P. (1992) Kinetic Scheme of the NonEquilibrium Discharge in Nitrogen-Oxygen Mixtures Plasma Sources Sci. Technol., 1, 207-220.

17-Dragan, R. Mirosl, av, K., Mirjana, S. P., Milovan, S., Jelena. S., (2015) Properties of Argon-Nitrogen Atmospheric Pressure DC Arc Plasma, Plasma Chem Plasma Process, 35, 1071-1095.

18- Raju, G.G. (2006) Feature article - Collision cross sections in gaseous electronics part I: what do they mean?, IEEE Electrical Insulation Magazine, 22 (4), 5-23.

19-Pu, Y.K., Guo, Z.G., Kang, Z.D., Ma, J., Guan, Z.C., Zhang, G.Y., and Wang, E.G. (2002) Comparative characterization of high-density plasma reactors using emission spectroscopy from VUV to NIRJ, Pure Appl. Chem., 74 (3), 459-465.

20-Pu, Y.K., Guo, Z.G., Rehman, A.U., Yu, Z.D. and Ma, J. (2006) Tuning effect of inert gas mixing on electron energy distribution function in inductively coupled discharges, Plasma Phys. Control. Fusion, 48, 61-70.

21-Galaly, A.R. (2016) Similarity of Gas Percentage and Strength of Magnetic Field on the Electrical Characteristics Control of dc Plasma, British Journal of Applied Science \& Technology, 13(2) 1-12.

22-Sode, M., Selinger, T.S., and Jacob, W. (2013) Quantitative determination of massresolved ion densities in $\mathrm{H} 2-\mathrm{Ar}$ inductively coupled radio frequency plasmas, Journal of Applied Physics, 113, 093304.

23-Xiong, Q., $\quad$ Nikiforov, A.Y., González, M.Á, Leys, C., Lu, X.P., Xiong, Q., Nikiforov, A. Yu., Gonz'alez, M.A., Leys, Ch., and Lu, X. P. (2013) Characterization of an atmospheric helium plasma jet by relative and absolute optical emission spectroscopy, Plasma Sources Sci. Technol., 22, 015011, 1-13.

24-Khan, F.U., Rehman, N.U., Naseer, S., Naveed, M.A., Qayyum, A., Khattak, N.A.D., and Zakaullah, M. (2009) Diagnostic of $13.56 \mathrm{MHz}$ RF sustained Ar-N2 plasma by optical emission spectroscopy, Eur. Phys. J. Appl. Phys., 45, 11002, 1-8.

25-Qayyum, A., Zeb, S., Naveed, M.A., Rehman, N.U., Ghauri, S.A., Zakaullah, M. (2007) Optical emission spectroscopy of $\mathrm{Ar}-\mathrm{N}_{2}$ mixture plasma, J. Quant. Spect. Radiat. Transfer, 107 (3), 361-371.

26-Hotop, H., Kolb, E., Lorenzen, J. (1979) The temperature dependence of penning ionization electron energy spectra: $\mathrm{He}\left(2^{3} S\right)$-ar, $\mathrm{N}_{2}, \mathrm{NO}, \mathrm{O}_{2}$, $\mathrm{N}_{2} \mathrm{O}, \mathrm{CO}_{2}$, Journal of Electron Spectroscopy and Related Phenomena, 16 (3), 213-243.

27- Flores, O., Castillo, F., Martinez, H., Villa, M., Villalobos, S. and Reyes, P. G. (2014) Characterization of direct current He-N2 mixture plasma using optical emission spectroscopy and mass spectrometry, Physics of Plasmas, 21, 053502, 1-6.

28-Timmermans, E.A.H., Thomas, I.A.J., Jonkers, J., Hartgers, E., van der Mullen, J.A.M., Schram, D. C. (1998) The influence of molecular gases and analytes on excitation mechanisms in atmospheric microwave sustained argon plasmas, Fresenius J. Anal. Chem., 362, 440-446.

29-Song, M.A., Lee, Y.W., and Chung, T.H., (2011). Characterization of an inductively coupled nitrogenargon plasma by Langmuir probe combined with optical emission spectroscopy, Physics of Plasma, 18, 023504, 1-12,

30-Younus, M. Rehman, N.U., Shafiq, M., Hussain, S.S., Zakaullah, M. and Zaka-ul-Islam, M. (2016) Characterization of RF He-N2/Ar mixture plasma via Langmuir probe and optical emission spectroscopy techniques, Physics of Plasmas, 23 (8), 083521, 1-9. 